\title{
Increased toxin expression in a Clostridium difficile mfd mutant
}

\author{
Stephanie E. Willing ${ }^{1,2}$, Emma J. Richards', Lluis Sempere ${ }^{2}$, Aaron G. Dale', Simon M. Cutting ${ }^{2}$ \\ and Neil F. Fairweather ${ }^{1 *}$ (D)
}

\begin{abstract}
Background: The symptoms of Clostridium difficile infection are mediated primarily by two toxins, TcdA and TcdB, the expression of which is governed by a multitude of factors including nutrient availability, growth phase and cell stress. Several global regulators have been implicated in the regulation of toxin expression, such as CcpA and CodY.

Results: During attempts to insertionally inactivate a putative secondary cell wall polysaccharide synthesis gene, we obtained several mutants containing off-target insertions. One mutant displayed an unusual branched colony morphology and was investigated further. Marker recovery revealed an insertion in $\mathrm{mfd}$, a gene encoding a transcription-coupled repair factor. The $\mathrm{mfd}$ mutant exhibited pleiotropic effects, in particular increased expression of both toxin $A$ and $B(T c d A$ and $T c d B)$ compared to the parental strain. Western blotting and cellular cytotoxicity assays revealed increased expression across all time points over a $24 \mathrm{~h}$ period, with inactivation of $\mathrm{mfd}$ resulting in at least a 10 fold increase in cell cytotoxicity. QRT-PCR demonstrated the upregulation of both toxins occurred on a transcriptional level. All effects of the $\mathrm{mfd}$ mutation were complemented by a plasmid-encoded copy of $\mathrm{mfd}$, showing the effects are not due to polar effects of the intron insertion or to second site mutations.
\end{abstract}

Conclusions: This study adds Mfd to the repertoire of factors involved in regulation of toxin expression in Clostridium difficile. Mfd is known to remove RNA polymerase molecules from transcriptional sites where it has stalled due to repressor action, preventing transcriptional read through. The consistently high levels of toxin in the $C$. difficile $m f d$ mutant indicate this process is inefficient leading to transcriptional de-repression.

Keywords: Clostridium difficile, Toxin A, Toxin B, Transcriptional roadblock, mfd, CcpA, Transcription-repair coupling factor

\section{Background}

Clostridium difficile is an anaerobic, spore-forming Grampositive pathogen that is now recognized as the leading cause of antibiotic-associated diarrhea in health care settings [1]. The incidence and apparent severity of $C$. difficile infection (CDI) rose in the mid-2000s, in part due to the circulation of strains resistant to the newer fluoroquinolone antibiotics [2, 3]. The infectious agent is the spore [4], which is remarkably resistant to heat, disinfectants and antimicrobial agents. Treatment of patients with antibiotics dramatically alters their gut microbiota [5] and this perturbation can cause loss of colonization resistance, allowing indigenous and exogenous pathogens to colonize and cause

\footnotetext{
* Correspondence: n.fairweather@imperial.ac.uk

'Department of Life Sciences, Centre for Molecular Bacteriology and

Infection, Imperial College London, London SW7 2AZ, UK

Full list of author information is available at the end of the article
}

disease [6]. Under these conditions, spores of $C$. difficile can germinate in the gut, and the resulting vegetative cells proliferate in high numbers. Vegetative cells and spores are excreted in large numbers and subsequent spore transmission can cause localized epidemics in health care settings.

The major virulence factors are two large toxins, TcdA (toxin A) and TcdB (toxin B). All toxigenic strains produce toxin $B$ and a large percentage of strains also produce toxin A [7]. These toxins have a similar structure and mode of action; the toxins are large, multi-domain proteins encoding glucoslytransferase and cysteine protease activities together with a repetitive receptor binding domain [8]. The toxins are released from bacteria in the gut lumen and are taken up by receptor-mediated endocytosis into enteric cells. Recent evidence suggests that additional receptor binding activity could be encoded within the central translocation domain [9]. Once internalized into vesicles, the 
cysteine protease activity is required to release the Nterminal glucosyltransferase domain from the adjacent protease domain, an activity dependent on cytosolic inositol-6-phosphate [10].

The toxin genes $t c d A$ and $t c d B$ are encoded within a genomic locus, PaLoc, with three other genes: $t c d R, t c d E$ and $t c d C$ [11]. The regulation of toxin synthesis is complex, with multiple forms of regulation evident. Toxin expression is related to the growth phase of the bacterium, with maximal expression occurring in the late-logarithmic phase of growth [12]; a quorum sensing molecule that may be the main mediator of this level of regulation was recently identified [13]. The toxins are under the control of the Gram-positive global transcriptional regulator CodY $[14,15]$. CodY binds to the promoter upstream of $t c d R$ [15], a gene specifying an alternative sigma factor necessary for transcription from the $t c d A$ and $t c d B$ promoters, as well as to the $t c d R$ promoter itself [16]. CodY also regulates over 150 other genes in C. difficile, and likely functions to monitor the expression of genes in response to nutrient sufficiency [14]. Several environmental and nutritional factors influence toxin expression including sub-inhibitory levels of antibiotics, the redox potential and the amino acid content of the medium. Spo0A, a transcriptional regulator essential for sporulation in B. subtilis and C. difficile, negatively regulates toxin production, with spoOA mutants producing increased levels of toxins $\mathrm{A}$ and $\mathrm{B}$ in some strains of $C$. difficile $[4,17]$. Notably, toxins A and B are also subject to carbon catabolite repression (CCR), their expression being markedly reduced in the presence of rapidly metabolizable sugars such as glucose [12]. In Gram-positive bacteria CCR is mediated by the transcriptional regulator CcpA. Genetic inactivation of components of the CCR signal transduction pathway results in de-repression of toxin expression in the presence of glucose, showing uptake of glucose is required for toxin repression [18]. CcpA binds to genetic elements within the $C$. difficile PaLoc, but recognizes sequences distinct from those of the well characterized cre (catabolic repression elements) sites recognized by $B$. subtilis CcpA. In $C$. difficile, five $c r e C D$ binding sites are found within the PaLoc: two upstream of the translational start site of $t c d R$, one upstream of $t c d B$, one inside $t c d A$ and one inside $t c d C$ [18]. Finally, Clostridium difficile toxins are regulated by the second messenger cyclic di-GMP [19]. Increased intracellular levels of cyclic di-GMP repress expression of $t c d A, t c d B$ and $t c d R$, an effect likely mediated by the alternative sigma factor SigD. SigD directly activates $t c d R$ expression and, as di-GMP lowers the levels of SigD, TcdR levels fall and toxin gene expression is reduced.

Transcription-repair coupling factor (TRCF), also known as Mfd in bacteria (mutation frequency decline), is a highly conserved protein that links the processes of nucleotide excision repair and transcription elongation [20]. In E. coli the Mfd protein is $130 \mathrm{kDa}$ and consists of 8 domains with two functional modules; an N-terminal module homologous to UvrB that recruits DNA repair proteins and a Cterminal module that possesses ATPase-dependent DNA translocase motor activity [21, 22]. RNA polymerase (RNAP) molecules that stall at DNA lesions are removed by the translocase activity of Mfd. The removal of stalled RNAP is not confined to DNA lesions, but is applicable to RNAP stalled for other reasons including nucleotide starvation or by blockage by other DNA bound proteins such as transcriptional repressors (reviewed in [23]). In B. subtilis, a Tn10 insertional mutation within $m f d$ has been shown to partially relieve CCR at cre elements that are sufficiently promoter distal to form transcriptional roadblocks by recruitment of CcpA [24]. Similarly, Mfd inactivation in B. subtilis partially relieves CodY-mediated transcriptional repression at post-promoter sites where this regulator can form transcriptional roadblocks that prevent RNA polymerase progression [25].

In this study, we characterize an insertional mutant in the $C$. difficile $m f d$ gene. This mutant has abnormal colony morphology and produces a higher level of toxins A and $\mathrm{B}$ than its parent strain.

\section{Results}

As part of a study into the $C$. difficile cell wall, we attempted to use a group II intron and an erythromycin resistance marker to target and inactivate the gene CD2775, located in a gene cluster downstream of $\operatorname{sip} A$ encoding the major S-layer protein in strain $630 \mathrm{Aerm}$ [26]. No insertions into CD2775 were obtained, perhaps because this gene is essential under the conditions of growth we employed. However some erythromycin resistant mutants were obtained, presumably where the group II intron had inserted into genes containing sequences related to the target sequence of CD2775. One of these mutants, designated 630-911 and subsequently mfd::erm (see below), had an interesting colony morphology on BHIS agar, with colonies displaying a highly branched structure in comparison to the compact colonies obtained with the wild type parent $630 \Delta e r m$ (data not shown). Colony morphologies were studied further using media of a more defined composition. On TY agar (without glucose), the $m f d$ mutant colonies appeared slightly smaller than the parental strain, but on TYG agar (containing glucose) the mutant colonies were considerably larger and displayed a highly branched structure (Fig. 1a). Cells from cultures grown in TY or TYG liquid cultures were examined using phase contrast microcopy. When grown in either medium, the cells of the mutant appeared longer than the parental strain, up to $10 \mu \mathrm{m}$ in length and slightly more curved (Fig. 1b).

\section{Strain 630-911 contains a defect in the mfd gene}

To investigate the phenotype of the mutant further, cell wall extracts and supernatants were prepared from cultures 


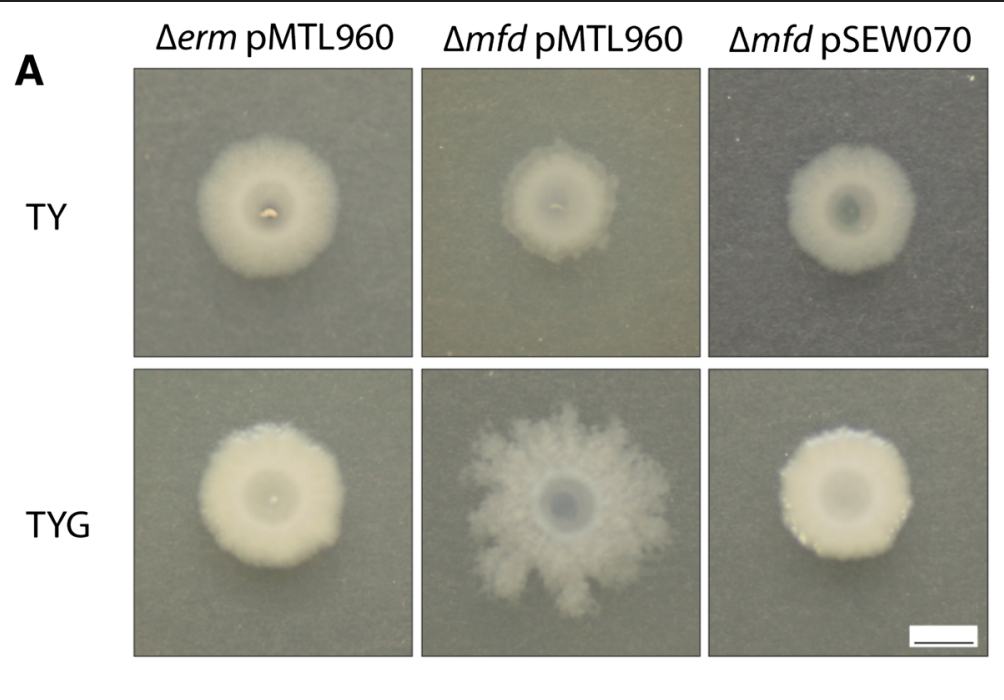

B

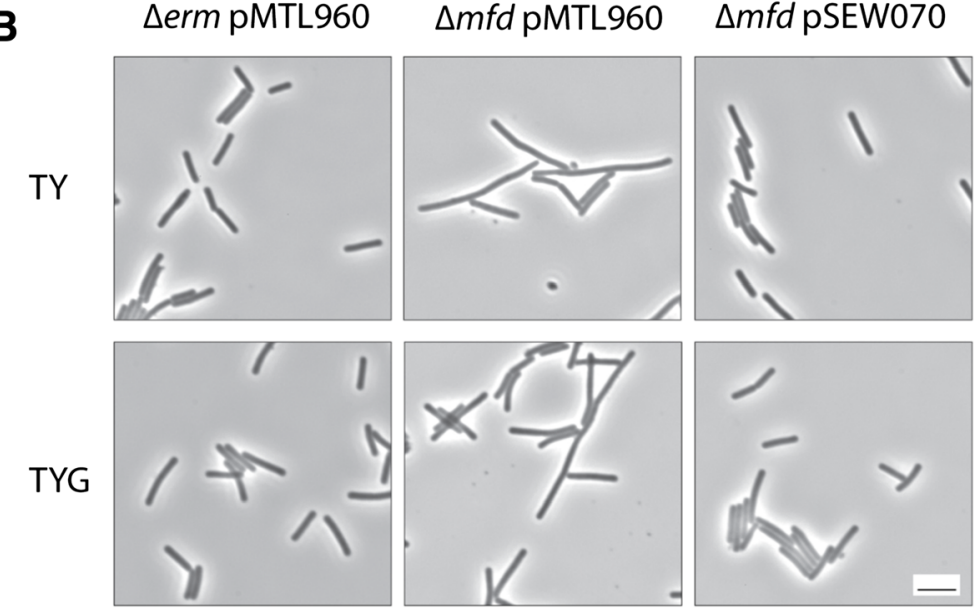

$\triangle m f d$ pMTL960

$\triangle m f d$ pSEW070

Fig. 1 Colony and cellular morphology of the C. difficile mfd mutant. a Liquid cultures (1 $\mu$ l) of strains $630 \Delta$ erm and the mfd mutant containing plasmid vector alone (pMTL960) or with the $\mathrm{mfd}$ gene (pSEW070) as appropriate were spotted on to TY or TYG agar and grown for 3 days. Representative colonies were photographed. Bar $=1 \mathrm{~cm}$. b Cultures of parental strain $630 \Delta$ erm and the mfd mutant containing pMTL960 vector or pSEW070 were grown in TY or TYG broth and photographed under phase contrast microscopy. Bar $=5 \mu \mathrm{m}$

of the 630-911 (mfd) mutant and the parental strain grown in BHIS broth and were analyzed by SDS-PAGE (Fig. 2). No differences in the cell wall protein profiles were apparent, aside from the appearance of bands at $\sim 42 \mathrm{kDa}$ and $\sim 116 \mathrm{kDa}$ in the $\Delta e r m$ strain. These are the products of $c w p V$, a phase variable gene that results in variable levels of CwpV proteins in the cell wall and which undergoes intramolecular autoproteolysis [27, 28]. However, in the supernatants of the $m f d$ mutant, an increased level of a large protein of over $212 \mathrm{kDa}$ was observed, which was not seen in strain $630 \Delta \mathrm{erm}$. Mass spectrometry of a tryptic digest of this protein revealed it to be derived from toxin A (TcdA; data not shown and see below).

To localize the mutation in the mutant, genomic DNA was prepared and digested with EcoRV, ClaI or HindIII. The digests were ligated with plasmid pBluescript cleaved with the same enzyme and, after ligation, E. coli transformants were selected on erythromycin to clone the locus into which the intron and the erm gene had inserted. Sequence analysis of plasmids revealed the presence of the erm gene and C. difficile DNA encoding the ORF CD3501, indicating this gene as the site where the intron had inserted. Insertion within CD3501 between basepairs 1412 and 1413 was subsequently confirmed by PCR using primers flanking the insertion site, and Southern blot confirmed this to be the only ClosTron insertion site (data not shown). CD3501 encodes $m f d$, a transcription-repair coupling factor (TCRF) [29]. TCRFs are widely conserved in nature and function to relieve stalled RNA polymerase molecules at regions of DNA damage, increasing the rate of excision of UvrABC exonucleases (see Introduction).

The $m f d$ gene is present in a region of the chromosome containing a putative type IV pilus operon, a peptidyl tRNA 


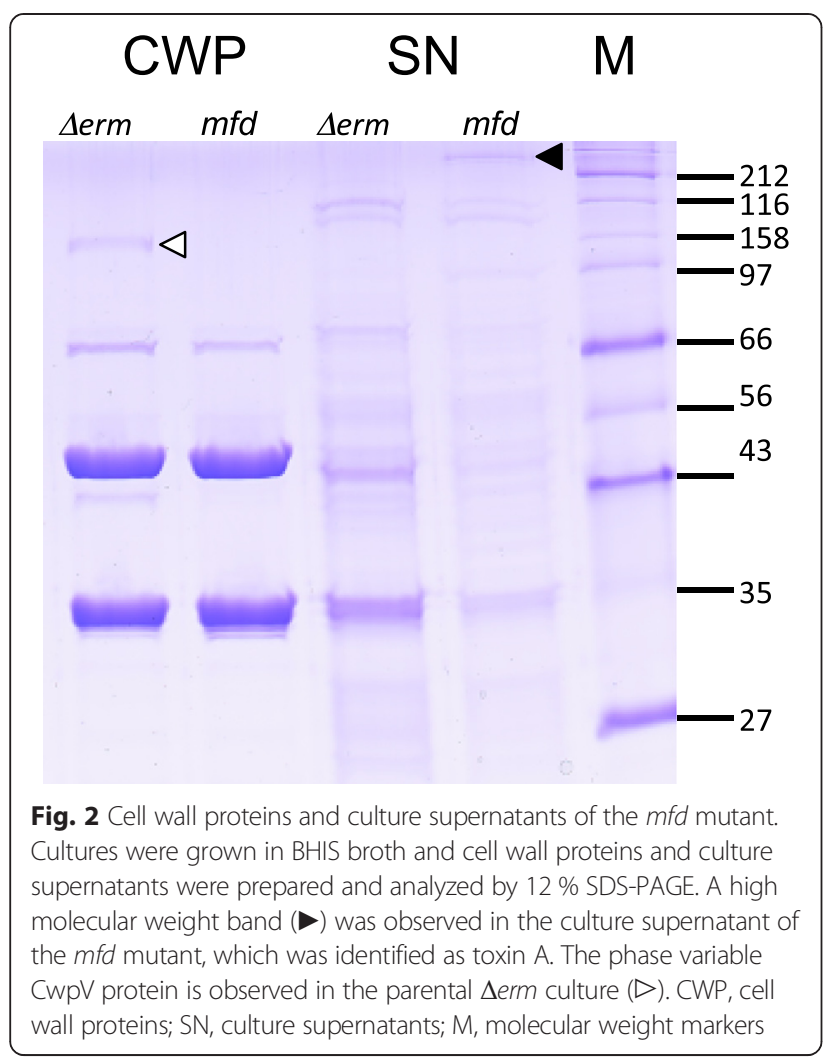

isomerase $p t h$ and the putative chaperone prsA (Fig. 3). To ensure that the mutant phenotype observed was not due to a polar effect on a downstream gene, the $m f d$ gene was complemented by cloning the wild-type $m f d$ gene from strain $630 \Delta e r m$ in an E. coli - C. difficile shuttle vector under control of the constitutive promoter Pcwp2 [30] to create pSEW070. When introduced into the $m f d$ mutant, pSEW070 conferred a wild-type colony phenotype (Fig. 1a) and under phase contrast microscopy the cells had the appearance of the wild type strain, with no elongated cells visible (Fig. 2b). When culture supernatants were analyzed by SDS-PAGE, the $>212 \mathrm{kDa}$ TcdA band was no longer visible in the complemented strain (see below) demonstrating that these phenotypes are due solely to the disruption of $m f d$. Western blotting with anti-TcdA and anti-TcdB confirmed the over-expression of TcdA and demonstrated that $\mathrm{TcdB}$ was also over-expressed (see below).
The mfd mutant over-produces toxins $\mathrm{T} c \mathrm{dA}$ and $\mathrm{TcdB}$

The quantities of functionally active $T c d A$ and $T c d B$ present in bacterial cell lysates and in culture supernatants were determined by a cytotoxicity assay using HT29 and Vero cells, lines that are differentially sensitive to TcdA and TcdB, respectively [31, 32]. When applied to these cell lines, the toxins induce cell rounding which can be scored by enumeration of cells by microscopy. As shown in Fig. 4, the levels of TcdA and TcdB in the mfd mutant were consistently higher than in the parental strain 630 $\mathrm{erm}$ at all time points. The toxin levels observed in the $m f d$ mutant varied according to time point and culture conditions, but in all cases were over 10 fold higher than the wild-type or genetically complemented samples. Although variations in the fold increase of cytotoxicity of the mfd mutant to the parental control and the complemented mutant were evident, the $m f d$ mutant consistently produced higher levels of TcdA and TcdB throughout growth, and this was seen in both cell lysates and in culture supernatants. Importantly, in the complemented mutant the levels of both toxins were similar to the parental cells.

To further investigate the production of toxins TcdA and TcdB by the $m f d$ mutant, $630 \Delta e r m$, the $m f d$ mutant and its complement containing pSEW070 were grown in TY or TYG and toxin levels in cell lysates and in culture supernatants analyzed by Western blotting. As shown in Fig. $5 \mathrm{a}$, a prominent band over $212 \mathrm{kDa}$ was visible by Coomassie blue staining of cell lysates of the $m f d$ mutant extracted at all time points. This band was identified as TcdA (see Fig. 2). The band was not visible in the parental strain or the complemented mutant at $6 \mathrm{~h}$, but was visible in the wild-type strain and complemented mutant at 12,18 and $24 \mathrm{~h}$, but at considerably lower intensity than in the $m f d$ mutant strain. In the culture supernatants, an equivalent band was visible at 12,18 and $24 \mathrm{~h}$, but again at all time points the intensities of the bands seen from the $m f d$ mutant were greater than those in the wild-type or complemented strain. As TcdA and TcdB are known to be co-regulated [12] and to investigate whether TcdB expression was also up-regulated in the $m f d$ mutant, we used Western blotting to analyse the expression of both toxins. The results were similar to those seen by Coomassie blue staining and showed high level expression of TcdA in the mfd mutant compared to the wild type or complemented

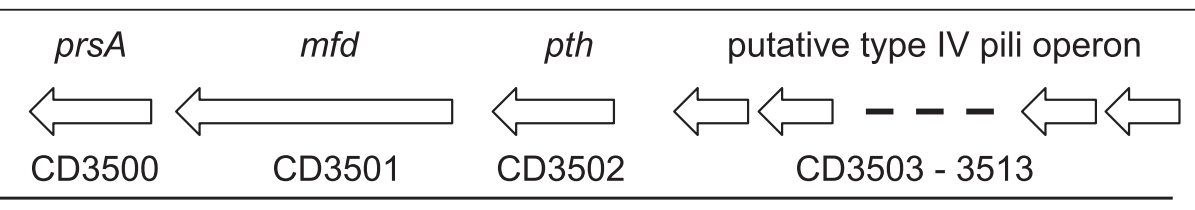

Fig. 3 Genome region of $C$. difficile 630 at the $m f d$ locus. Downstream of $m f d$ (CD3501) is prs $(C D 3500)$ a putative chaperone, while upstream is pth (peptidyl-tRNA hydrolase; CD 3502) and a multi-gene type IV pili locus (CD3503 - CD3513). All genes are transcribed in the same direction (right to left in this diagram). CD gene numbers are given below the genetic symbols 

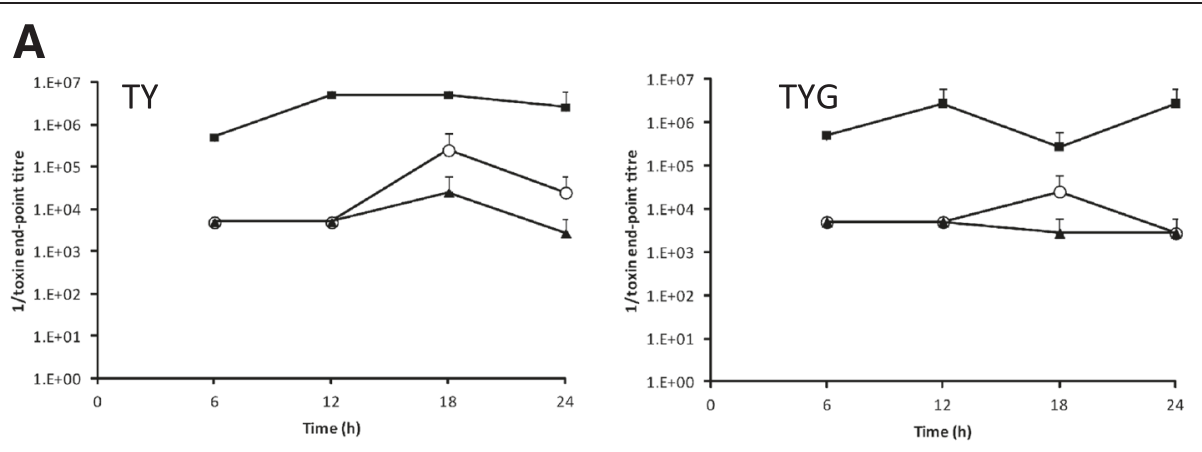

\section{B}
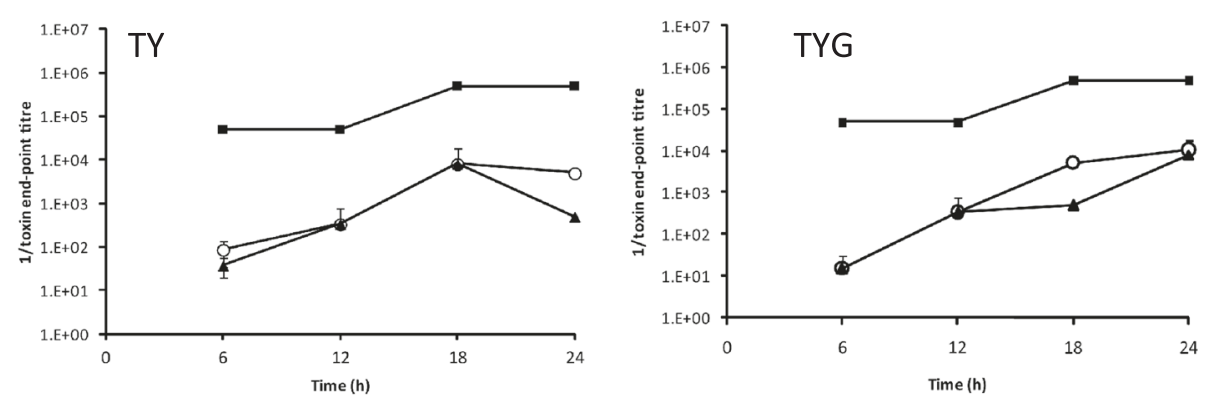

C
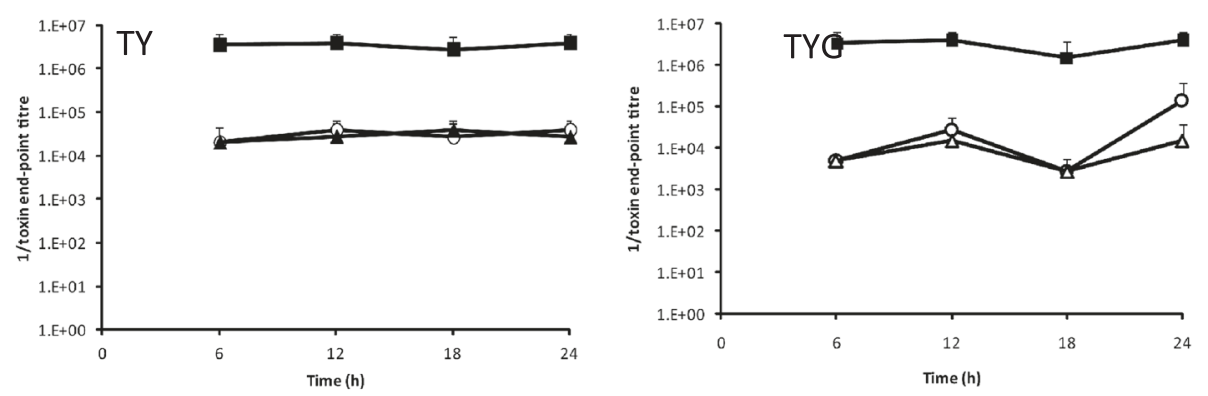

D
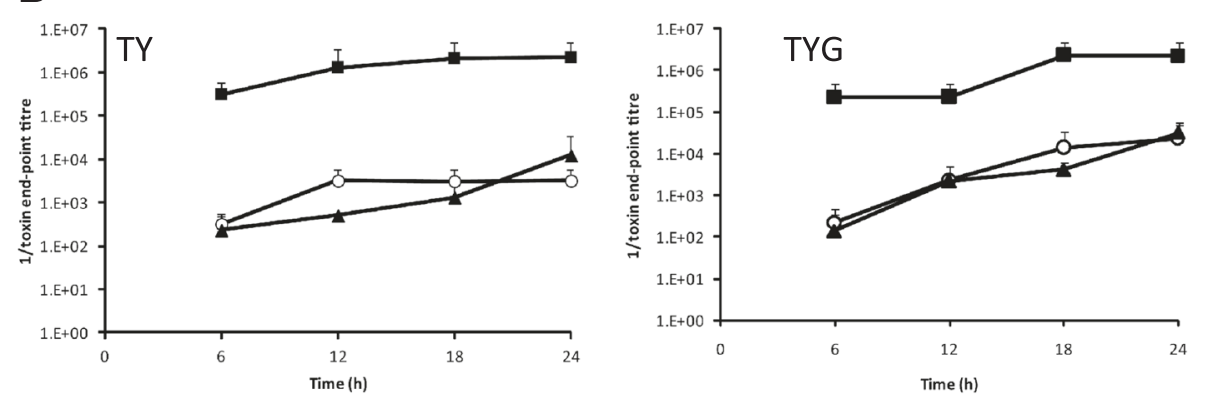

Fig. 4 Cytotoxicity levels of toxins A and B in the $\mathrm{mfd}$ mutant. Cultures of 630 $\mathrm{\Delta erm}$, the mfd mutant or the complement were grown in TY or TYG media. Cell lysates and culture supernatants were prepared at various time points. Samples were normalized for optical density of the culture and analyzed for the presence of toxins A and B by cytotoxicity on HT29 cells (toxin A) or Vero cells (toxin B). Panels: a bacterial lysates on Vero cells; b bacterial supernatants on Vero cells; $\mathbf{c}$ bacterial lysates on HT29 cells; d bacterial supernatants on HT29 cells. Samples were standardized by $\mathrm{OD}$ at point of collection. o, 630 $\mathrm{\Delta erm}$; $\mathrm{mfd}$ mutant; $\boldsymbol{\Delta}$ complement. Data represents the mean of two biological repeats and at least two technical repeats and error bars represent standard deviations

strains (Fig. 5b). TcdB was also detectable by Western blotting (Fig. 5c). Similarly to TcdA, the levels of TcdB were maximal in the cell lysates of the $m f d$ mutant compared to the parental or complemented controls. Levels of expression did not completely mirror those of TcdA, as levels were maximal at $24 \mathrm{~h}$ and those at $18 \mathrm{~h}$ appeared lower than at $12 \mathrm{~h}$. Only at $24 \mathrm{~h}$ was expression of TcdB apparent in the supernatants, and only in the $m f d$ mutant strains.

To verify that the increased production of toxins A and $B$ was due to increased transcription, RNA was extracted 


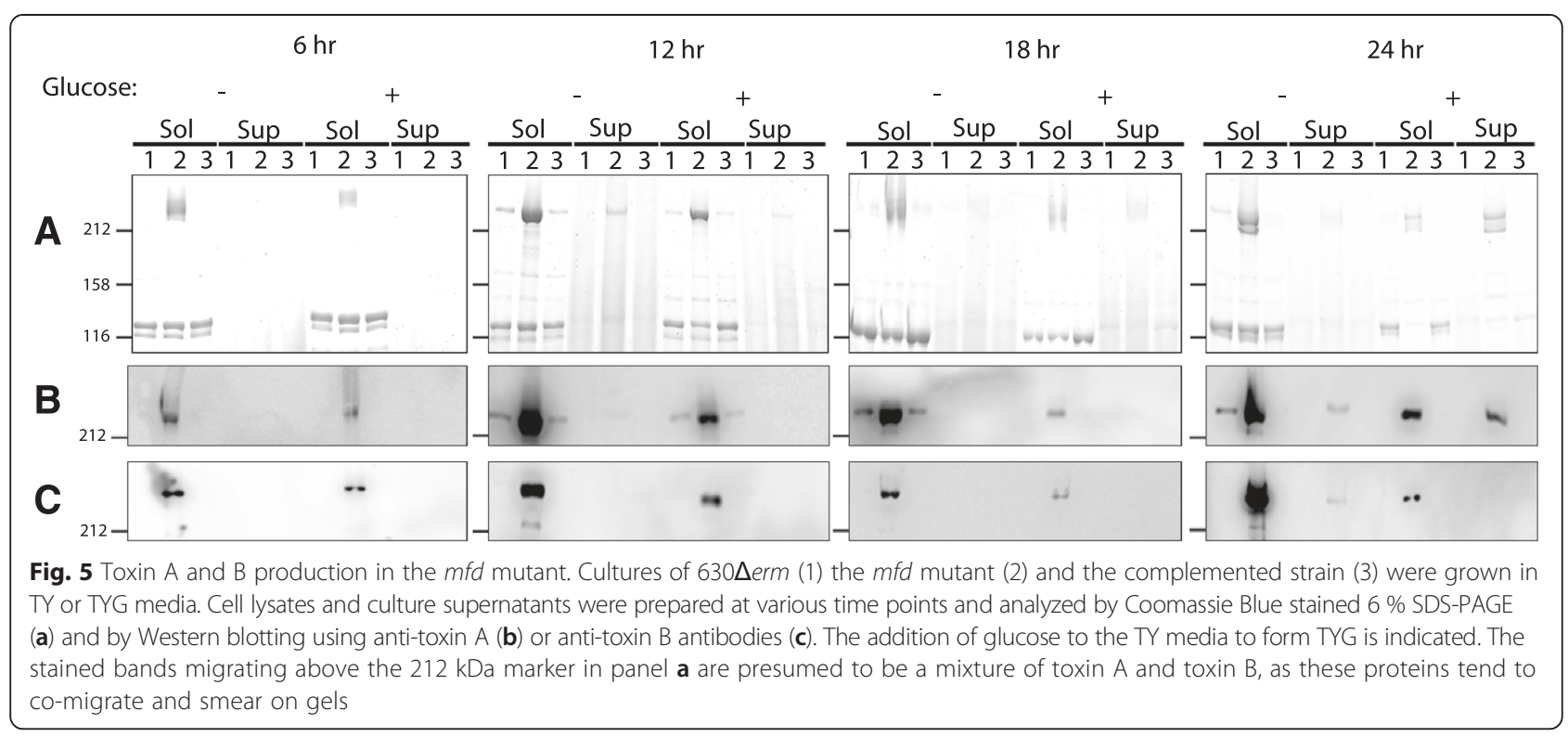

from $630 \Delta$ erm and the $m f d$ mutant after $6 \mathrm{~h}$ growth in either TY or TYG, and quantitative RT-PCR performed. As shown in Fig. 6 a significant increase in transcript levels of both $t c d A$ and $t c d B$ was seen in the $m f d$ mutant compared to $630 \Delta$ erm strain when grown in TY $(p \leq 0.01)$ or TYG $(p<0.05)$. This demonstrates that an increase in toxin production is occurring on a transcriptional level in the $m f d$ mutant both in the presence and absence of glucose. Overall, our results demonstrate increased expression of toxins TcdA and TcdB in the $m f d$ mutant, and that this is due solely to the presence of the insertional mutation in the $m f d$ gene.

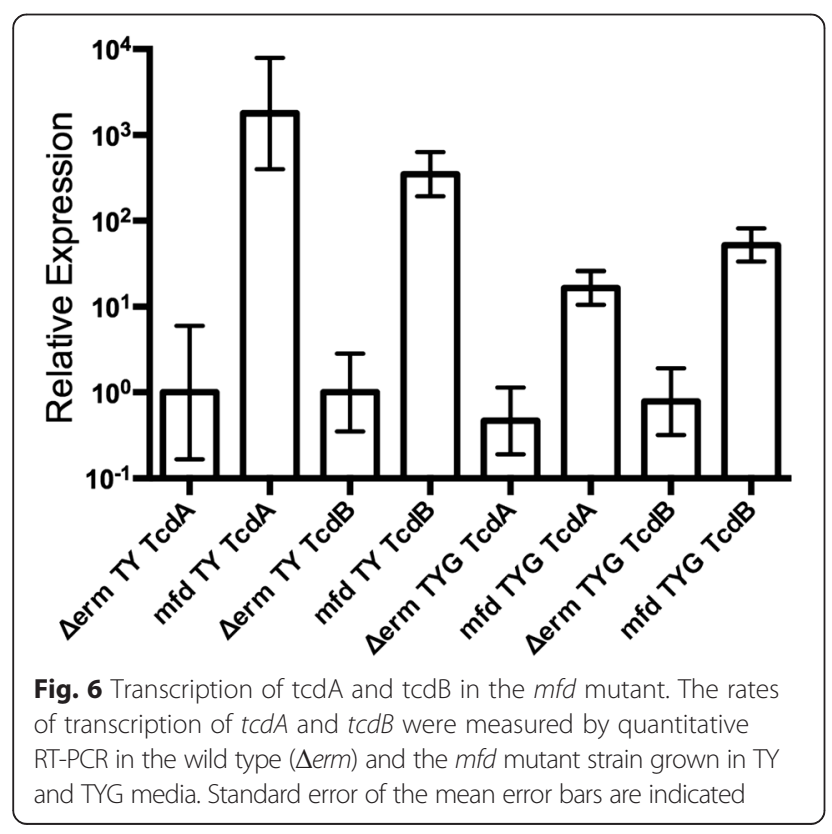

The mfd mutant does not exhibit a pleiotropic phenotype As TCRFs can be involved in a diversity of cellular activities $[24,25]$ we investigated whether our $C$. difficile $m f d$ mutant exhibited phenotypes other than the unusual colony morphology and toxin upregulation. The growth rates of the wild-type and mutant strains were similar, however when grown in TY medium (Fig. 7a), the $m f d$ mutant ceased growth almost completely at the end of exponential phase (at $10 \mathrm{~h}$ ) whereas the wild type strain and the complemented strain continued to grow for a further $12 \mathrm{~h}$ (Fig. 7b). In B. subtilis, it has been reported that inactivation of $m f d$ results in a $40 \%$ decrease in sporulation efficiency compared to WT [24]. However, in contrast to B. subtilis, the $C$. difficile mfd mutant did not show a defect in sporulation (data not shown). Finally, we also investigated flagella-mediated motility, and found no obvious defect in the $m f d$ mutant (data not shown).

\section{Discussion}

Our use of marker recovery revealed that an uncharacterized mutation was within $m f d$ (CD3501), encoding a TCRF that directs the preferential repair of template strand DNA of transcribed genes following certain types of DNA damage. In other species, it is known that Mfd acts through the combined functions of a C-terminal domain which can interact with, and subsequently displace, stalled RNA polymerases and an $\mathrm{N}$-terminal domain with homology to UvrB which recruits the nucleotide excision repair machinery, UvrABC, via interaction with UvrA [33]. Thus, with the combined actions of these two domains, Mfd functions to restore transcription and repair mutations before they become fixed in the genome by replication. While the role of Mfd as a repair factor is well established, it has also been 

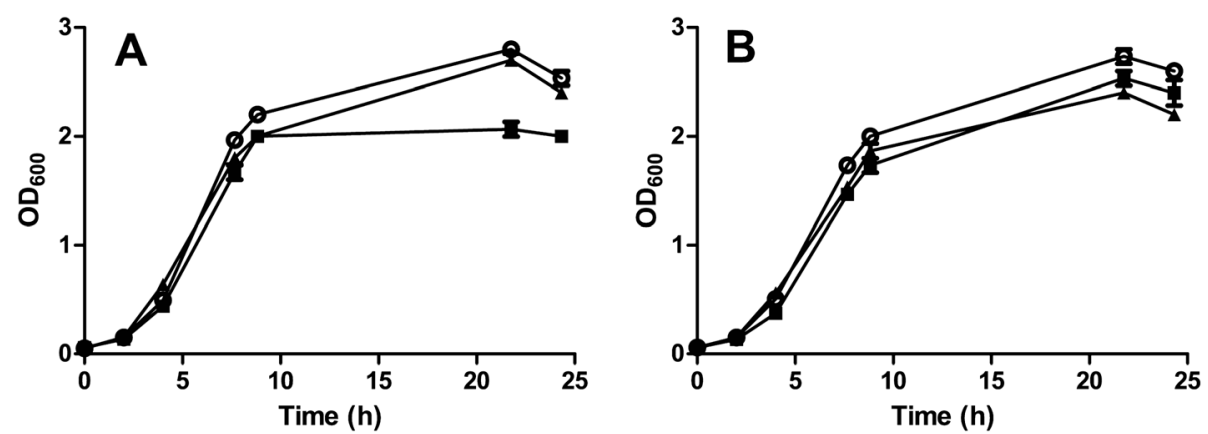

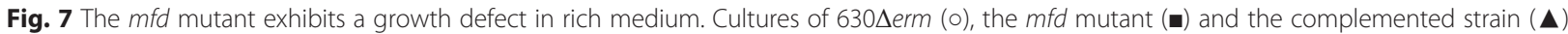
were cultured in TY (a) or TYG (b) media containing $15 \mu \mathrm{g} / \mathrm{ml}$ thiamphenicol and their growth measured. The 630 $\Delta$ erm and $\mathrm{mfd}$ strains contained the plasmid PMTL960 and the complemented strain the plasmid pSEW070

shown to have a role in adaptive mutagenesis. In B. subtilis the Mfd protein is important for stationary phase mutagenesis [34] and in Campylobacter jejuni Mfd promotes fluroquinone resistance generating mutations [35].

In Bacillus subtilis, a forward genetics screen for mutants deficient in CCR isolated an mfd mutant [24]. In this mutant, partial relief of CCR occurred for genes with cre sites downstream of the promoter, but not those with promoter proximal cre sites. This suggested that these cre sites lead to RNA polymerase stalling at a roadblock, which can be relieved by Mfd. Without Mfd to release the polymerase, the RNA polymerase will in some instances eventually overcome the roadblock as the repressor protein dissociates, resulting in increased transcription of the gene [35]. Promoter proximal sites prevent transcription initiation and therefore do not cause RNA polymerase to stall, requiring no involvement from Mfd. Similarly, Mfd has been implicated in CodY-mediated repression of genes containing downstream CodY-binding sites [25]. The ability of the Mfd to displace RNA polymerases stalled at transcriptional roadblocks makes Mfd important in maintaining the efficacy of this type of transcriptional repressor.

How does Mfd act in controlling the level of toxin gene expression in C. difficile? CodY and CcpA are known repressors of toxin production and binding sites within the PaLoc have been identified for both these proteins. It is possible that Mfd acts by relieving RNA polymerase molecules stalled at roadblocks created by $\operatorname{CodY}$ and CcpA. This is consistent with the observed increases in transcription, and the large increases in toxin A and toxin $\mathrm{B}$ production in the $m f d$ mutant. In our experiments we saw only a small effect of glucose in repression of toxin production in the wild-type cultures, which complicates the analysis of the mfd mutant in regard to the role of CcpA. In the $C$. difficile mfd mutant it is apparent that glucose-independent de-repression occurs, as we observe increased transcription of $t c d A$ and $t c d B$ and increased production of both toxins as measured by cell cytoxicity and Western blotting in the mfd mutant compared to the wild type when cultures are grown in TY medium. A similar observation was made for a $c c p A$ mutant and it was suggested that CcpA could also act in a glucose-independent manner [36]. It is possible we are witnessing a similar effect here. Alternatively, it is possible that relief of CodY or other as yet unknown transcription roadblocks is also occurring [15].

We have not been able to identify the factor responsible for the colony morphology phenotype or the elongated cells. However, relief of transcriptional roadblocks is certain to have impacts on genomic loci other than the PaLoc. In contrast to B. subtilis, we did not observe a defect in sporulation for the $m f d$ mutant, adding to the many differences observed in the sporulation pathway between C. difficile and B. subtilis [37]. Importantly, the observed phenotypes of the $m f d$ mutant were complemented upon introduction of a plasmid-encoded copy of $m f d$. This study adds another layer to the regulatory network governing toxin synthesis and secretion and is to our knowledge the first direct implication of Mfd with toxin production and hence virulence of this pathogen. Finally we note that an mfd mutant could be of utility in producing increased levels of toxins for commercial applications.

\section{Conclusions}

We have identified that a mutation in the C. difficile mfd gene results in abnormal colony morphology and a large increase in the production of toxins A and B. Increased transcription of the $t c d A$ and $t c d B$ genes is observed, suggesting that in the $m f d$ mutant there is relief of transcriptional repression perhaps mediated by CcpA or CodY.

\section{Methods}

Bacterial strains, plasmids and culture conditions

C. difficile strains and plasmids are described in Table 1. Strains were grown and maintained at $37{ }^{\circ} \mathrm{C}$ in a Whitley DG250 anaerobic workstation under anaerobic conditions $\left(10 \% \mathrm{H}_{2}, 10 \% \mathrm{CO}_{2}, 80 \% \mathrm{~N}_{2}\right.$ ) (D. Whitley, Yorkshire, UK). C. difficile strains were cultured in tryptose-yeast 
Table 1 Strains and plasmids used in this study

\begin{tabular}{|c|c|c|}
\hline Strain or plasmid & Relevant characteristics & Source or reference \\
\hline \multicolumn{3}{|l|}{ C. difficile strains } \\
\hline $630 \Delta e r m$ & Wild-type strain & $\begin{array}{l}\text { Obtained from } \\
\text { Peter Mullany [29] }\end{array}$ \\
\hline 630-911 (mfd mutant) & 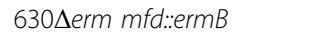 & This study \\
\hline $630 \operatorname{tcd} A \operatorname{tcd} B$ & 630 $\Delta$ erm tcdA::catP tcdB::erm & $\begin{array}{l}\text { Obtained from } \\
\text { Nigel Minton; [43] }\end{array}$ \\
\hline \multicolumn{3}{|l|}{ Plasmids } \\
\hline pMTL960 & $\begin{array}{l}\text { Plasmid vector for } \\
\text { complementation studies }\end{array}$ & $\begin{array}{l}\text { Obtained from } \\
\text { Nigel Minton; [38] }\end{array}$ \\
\hline pSEW070 & $\begin{array}{l}\text { pMLT960 carrying wild } \\
\text { type mfd gene under } \\
\text { control of Pcwp2 }\end{array}$ & This study \\
\hline
\end{tabular}

(TY) medium (3\% Bacto tryptose, $2 \%$ yeast extract), TYG (TY supplemented with $0.5 \%$ filter sterilized glucose) or BHIS (3.7 \% brain heart infusion, $0.5 \%$ yeast extract and $0.1 \%$ cysteine). For visualization of $C$. difficile colony morphology $3 \mu \mathrm{l}$ of each strain, normalized to OD 0.3, was spotted on to TY or TYG agar, grown for 3 days and imaged using a Canon EOS 450D camera. For solid media, agar was added to a final concentration of $1.5 \%$. For plasmid maintenance, media were supplemented with $15 \mu \mathrm{g} / \mathrm{ml}$ thiamphenicol when necessary. E. coli strains were grown in L-broth or on L-agar as described [38] and plasmids maintained by chloramphenicol $(30 \mu \mathrm{g} / \mathrm{ml})$. For visualization of $C$. difficile cell morphology, strains were grown overnight in either TY or TYG and imaged using a Nikon Eclipse E600 microscope fitted with a Nikon DMX1200 camera.

\section{Genetic techniques}

C. difficile genomic DNA was isolated as described previously [39] and was cleaved and ligated using conventional procedures [40]. To obtain fragments for cloning, PCR reactions were performed using KOD Hot Start polymerase (Novagen) using primers as detailed below. Standard PCR was performed using Taq polymerase (Sigma). For marker recovery, C. difficile 630 4 erm $m f d::$ erm genomic DNA was digested with restriction endonucleases and the fragments cloned into pBluescript cleaved with the same enzymes. After ligation, the products were transformed into $E$. coli NovaBlue (Merck) and transformants selected on L-agar containing $500 \mu \mathrm{g} / \mathrm{ml}$ erythromycin. Plasmid pSEW070 was created by amplification of the $m f d$ gene from $C$. difficile 630 $\mathrm{erm}$ using KOD polymerase with primers NF2234 and NF2298 and cloning into pMTL960 using the BamHI and SacI sites. Plasmids were conjugated into $C$. difficile firstly by transforming into $E$. coli CA434, selecting for chloramphenicol $(30 \mu \mathrm{g} / \mathrm{ml})$ resistance followed by conjugation into $C$. difficile $630 \Delta \mathrm{erm}$ and selection for thiamphenicol resistance $(15 \mu \mathrm{g} / \mathrm{ml})$ in the presence of clycloserine $(250 \mu \mathrm{g} / \mathrm{ml})$ to kill the $E$. coli donor cells.
ClosTron mutants were created using the methods described $[41,42]$. Briefly, the L1.LtrB intron present in plasmid pMTL007C-E5 was retargeted to CD2775 using the ClosTron web site (www.clostron.com) and the resulting plasmid pSEW035 constructed by DNA2.0. pSEW035 was transformed into E. coli CA434 and then conjugated into C. difficile $630 \Delta \mathrm{erm}$ selecting for thiamphenicol resistance $(15 \mu \mathrm{g} / \mathrm{ml})$. Thiamphenicol resistant colonies were restreaked on to erythromycin $(5 \mu \mathrm{g} / \mathrm{ml})$ to obtain colonies containing chromosomally integrated introns.

\section{RNA isolation}

RNA for quantitative real time PCR was extracted from $630 \Delta e r m$ and the $m f d$ mutant following $6 \mathrm{~h}$ growth in TY or TYG. $5 \mathrm{ml}$ of culture was added to $10 \mathrm{ml}$ of RNA protect (Qiagen) in the anaerobic chamber before 10 min centrifugation at $5000 \mathrm{x} \mathrm{g}, 4{ }^{\circ} \mathrm{C}$. RNA was purified using the FastRNA Pro Blue kit (BIO 101 Systems) and a FastPrep-24 automated homogenizer (MP Biomedical, $45 \mathrm{~m} / \mathrm{s}$, for $3 \mathrm{cy}-$ cles), followed by DNase treatment (TURBO DNA-free, Applied Biosystems). To verify removal of DNA, $16 \mathrm{~S}$ rRNA PCR amplification was carried out with $1 \mu \mathrm{g}$ of RNA. $1 \mu \mathrm{g}$ of RNA was processed using RETROscript First Strand Synthesis Kit (Ambion).

\section{Quantitative RT-PCR}

Quantitative real time PCR was performed using SYBR Green JumpStart Taq Ready Mix (Sigma), $50 \mathrm{mM}$ of gene specific primers (Table 2), $2 \mu$ l of cDNA obtained from $1 \mu \mathrm{g}$ of RNA as described above, and a Rotor-Gene 6000 real -time rotary analyzer (Corbett). SYBR ${ }^{\circ}$ Green reaction mixtures contained $500 \mathrm{nM}$ of each primer in a final volume of $20 \mu \mathrm{L}$ and were incubated for ten minutes at $95{ }^{\circ} \mathrm{C}, 40$ cycles at $95{ }^{\circ} \mathrm{C}$ for $30 \mathrm{~s}, 48{ }^{\circ} \mathrm{C}$ for $30 \mathrm{~s}$, $72{ }^{\circ} \mathrm{C}$ for $60 \mathrm{~s}$, and a final extension step at $72{ }^{\circ} \mathrm{C}$ for $3 \mathrm{~min}$. Melting curves were performed from 50 to $99^{\circ} \mathrm{C}$ reading fluorescence at $0.5{ }^{\circ} \mathrm{C}$ intervals. Mean $\mathrm{Ct}$ values

Table 2 Primers used in this study

\begin{tabular}{lll}
\hline $\begin{array}{l}\text { Primer } \\
\text { name }\end{array}$ & Sequence $\left(5^{\prime}\right.$ to 3') $^{\prime}$ & Used for \\
\hline SW78 & TCTACCACTGAAGCATTAC & qPCR for $t c d A$ \\
SW79 & TAGGTACTGTAGGTTATTG & qPCR for $t c d A$ \\
SW80 & ACCATATAGCTTTGTGATAGTGAAGGAAA & qPCR for $t c d B$ \\
SW81 & AAGAACTACATCAGGTAATTCAGATACAAA & qPCR for $t c d B$ \\
SW82 & GGATGATATGATGAAGGTTAGAAACCT & qPCR for rpoB \\
SW83 & CCCAATCCAAGTTCTTCTAGTTITG & qPCR for rpoB \\
NF408 & TCTTGAATATCAAAGGTGAGCCAGTACA & 16S RNA \\
& & amplfication \\
NF409 & TACAGCGTGGACTACCAGGGTATCTAAT & 16S RNA \\
& & amplfication \\
NF2234 & GATCGAGCTC AATATAATGGATAGTGAGAG & mfd amplication \\
NF2298 & GATCGAGCTC AATATAATGGATAGTGAGAG & mfd amplication \\
\hline
\end{tabular}


were normalized to $r p o B$, which was amplified using primers SW82 and SW83. Each reaction was performed in technical duplicate and relative expression values reported are representative of two biological replicates.

\section{Western blotting and mass spectrometry}

SDS-PAGE was carried out as described previously [38]. $6 \%$ or $12 \%$ acrylamide was used in the resolving gel as specified in the figure legends. For immunoblot analysis, proteins were transferred to Immobilon-PVDF membranes (Millipore) using a three-buffer semi-dry method according to the instructions provided by the manufacturer. Anti-Toxin A (PCG4.1, Novus Biologicals) was used in a 1:1000 dilution and rabbit anti-Toxin B (a gift from Ingo Just, Hannover Medical School) in a 1:5000 dilution in $3 \%$ milk powder (VWR) in PBS (VWR). Primary antibodies were detected by using horseradish peroxidase (HRP)-conjugated goat anti-mouse antibody at 1:1000 (Dako) and the SuperSignal West Pico chemiluminescent substrate (Thermo Scientific Pierce).

Identification of protein bands from SDS-PAGE was by mass spectrometry carried out at the Protein and Nucleic Acid Chemistry Facility of the University of Cambridge, Cambridge, United Kingdom. Samples were prepared according to the instructions given at http:// www3.bioc.cam.ac.uk/pnac/proteomics.html.

\section{HT29 and Vero cell cytotoxicity assays}

Overnight cultures of $C$. difficile in TY or TYG were used to inoculate media to a starting optical density at $600 \mathrm{~nm}$ of 0.05 . Culture supernatants and bacterial cell lysates were collected at $6,12,18$, and 24 h by centrifugation $\left(4000 \mathrm{~g}, 10 \mathrm{~min}, 4{ }^{\circ} \mathrm{C}\right)$. Supernatants were filtered through $0.2 \mu \mathrm{m}$ pore size units and concentrated on $3 \mathrm{kDa}$ molecular weight cut-off centrifugal filters (Amicon). Bacteria were washed once in Tris-buffered saline $(10 \mathrm{mM}$ Tris. $\mathrm{HCl}, \mathrm{pH} 7.5,150 \mathrm{mM} \mathrm{NaCl}$ ) and stored at $-80^{\circ} \mathrm{C}$. Bacteria were re-suspended in $\mathrm{PBS}$ and lysed by repeated freeze-thawing at $37{ }^{\circ} \mathrm{C}$. Lysates were centrifuged at 20, $800 \mathrm{~g}$ for $5 \mathrm{~min}$ and the supernatant removed into a fresh tube to obtain the soluble fraction. The preparations were stored at $-20{ }^{\circ} \mathrm{C}$. Samples were normalized by the addition of PBS to a final volume proportional to the optical density of the culture at the time of collection. For both soluble cell lysates and supernatants, an OD of 20 was diluted to a total volume of $50 \mu \mathrm{l}$ in PBS. Ten-fold serial dilutions of these samples were made in PBS and $20 \mu \mathrm{l}$ of each dilution was added to $80 \mu \mathrm{l}$ of fresh media above confluent HT29 or Vero cells giving an additional 1-in-5 dilution. Cells were incubated $\left(37^{\circ} \mathrm{C}, 5 \% \mathrm{CO}_{2}\right)$ with supernatants or lysates for $24 \mathrm{~h}$ before scoring toxin endpoint titers by examination using a Nikon Eclipse TS100 light microscope. Toxin end point-titers were taken as the first dilution at which cell morphology was indistinguishable from untreated controls.
PBS alone or supernatants prepared from an isogenic $t c d A$ $t c d B$ [43] did not cause morphological changes in either cell line.

The HT-29 line is reported as being sensitive to TcdA in the pg range and $\mathrm{TcdB}$ in the mg range, whereas the Vero line is sensitive to $T c d B$ in the pg range and TcdA in the ng range [32]. HT29 and Vero cells were cultured in Dulbecco's modified Eagle's medium (DMEM with $4500 \mathrm{mg} / \mathrm{l}$ glucose and sodium bicarbonate) supplemented with $10 \%(\mathrm{v} / \mathrm{v})$ fetal calf serum, $1 \mathrm{x}$ non-essential amino acids, $4 \mathrm{mM}$ L-glutamine and penicillin/streptomycin (Sigma). Confluent cell monolayers were prepared by seeding 96 well plates with $2 \times 10^{4}$ cells/well followed by $72 \mathrm{~h}$ growth $\left(37^{\circ} \mathrm{C}, 5 \% \mathrm{CO}_{2}\right)$.

\section{Availability of supporting data}

Additional data supporting the results shown and the strains and plasmids generated in this study are available from the authors.

\section{Abbreviations}

CDI: C. difficile infection; mfd: mutation frequency decline; CWP: Cell wall protein; PVDF: Polyvinylidene fluoride; CCR: Carbon catabolite repression; TCRF: Transcription-coupled repair factor.

\section{Competing interests}

The authors declare that they have no competing interests.

\section{Authors' contributions}

NF conceived and designed the study. SW, ER, AD and LS performed the experiments and, together with NF and SC, analyzed the data. SW and NF drafted the manuscript. All authors contributed to preparation of the final manuscript. All authors approved the final manuscript.

\section{Acknowledgments}

S.W. and E.R. were supported by BBSRC and MRC studentships, respectively. A.D. was funded by an MRC programme grant G0800170 to N.F. Work in the Cutting laboratory was funded by the MRC (DPFS MR/K015354/1) and the EU (HEALTH-F3-2013-601810. We thank Robert Fagan for useful discussions during this project, Nigel Minton for the $C$. difficile $t c d A t c d B$ mutant and Ingo Just for antibody to toxin B.

\section{Author details}

${ }^{1}$ Department of Life Sciences, Centre for Molecular Bacteriology and Infection, Imperial College London, London SW7 2AZ, UK. ${ }^{2}$ School of Biological Sciences, Royal Holloway University of London, Egham, Surrey TW20 OEX, UK.

Received: 25 June 2015 Accepted: 3 December 2015 Published online: 18 December 2015

\section{References}

1. Rupnik M, Wilcox MH, Gerding DN. Clostridium difficile infection: new developments in epidemiology and pathogenesis. Nat Rev Microbiol. 2009;7(7):526-36.

2. Loo VG, Poirier L, Miller MA, Oughton M, Libman MD, Michaud S, et al. A predominantly clonal multi-institutional outbreak of Clostridium difficile-associated diarrhea with high morbidity and mortality. N Engl J Med. 2005;353(23):2442-9

3. McDonald LC, Killgore GE, Thompson A, Owens Jr RC, Kazakova SV, Sambol $\mathrm{SP}$, et al. An epidemic, toxin gene-variant strain of Clostridium difficile. N Engl J Med. 2005;353(23):2433-41.

4. Deakin L, Clare S, Fagan RP, Dawson LF, Pickard DJ, West MR, et al. The Clostridium difficile SPO0A gene is a persistence and transmission factor. Infect Immun. 2012;80(8):2704-11. 
5. Dethlefsen $L$, Huse $S$, Sogin ML, Relman DA. The pervasive effects of an antibiotic on the human gut microbiota, as revealed by deep 165 rRNA sequencing. PLoS Biol. 2008;6(11):e280.

6. Lawley TD, Walker AW. Intestinal colonization resistance. Immunology. 2013;138(1):1-11.

7. Rupnik M. Heterogeneity of large clostridial toxins: importance of Clostridium difficile toxinotypes. FEMS Microbiol Rev. 2008;32(3):541-55.

8. Jank T, Aktories K. Structure and mode of action of clostridial glucosylating toxins: the ABCD model. Trends Microbiol. 2008;16(5):222-9.

9. Genisyuerek S, Papatheodorou P, Guttenberg G, Schubert R, Benz R, Aktories K. Structural determinants for membrane insertion, pore formation and translocation of Clostridium difficile toxin B. Mol Microbiol. 2011;79(6):1643-54.

10. Egerer M, Giesemann T, Jank T, Satchell KJF, Aktories K. Auto-catalytic cleavage of Clostridium difficile toxins $A$ and $B$ depends on a cysteine protease activity. J Biol Chem. 2007;282:25314-21.

11. Braun $V$, Hundsberger $T$, Leukel $P$, Sauerborn $M$, von Eichel-Streiber $C$. Definition of the single integration site of the pathogenicity locus in Clostridium difficile. Gene. 1996;181(1-2):29-38.

12. Dupuy B, Sonenshein AL. Regulated transcription of Clostridium difficile toxin genes. Mol Microbiol. 1998;27(1):107-20

13. Darkoh C, DuPont HL, Norris SJ, Kaplan HB. Toxin Synthesis by Clostridium difficile Is Regulated through Quorum Signaling. MBio. 2015;6(2):e02569.

14. Dineen SS, McBride SM, Sonenshein AL. Integration of metabolism and virulence by Clostridium difficile CodY. J Bacteriol. 2010;192(20):5350-62.

15. Dineen SS, Villapakkam AC, Nordman JT, Sonenshein AL. Repression of Clostridium difficile toxin gene expression by CodY. Mol Microbiol. 2007;66(1):206-19.

16. Mani N, Dupuy B. Regulation of toxin synthesis in Clostridium difficile by an alternative RNA polymerase sigma factor. Proc Natl Acad Sci U S A. 2001:98(10):5844-9.

17. Underwood S, Guan S, Vijayasubhash V, Baines SD, Graham L, Lewis RJ, et al. Characterization of the sporulation initiation pathway of Clostridium difficile and its role in toxin production. J Bacteriol. 2009;191(23):7296-305.

18. Antunes A, Camiade E, Monot M, Courtois E, Barbut F, Sernova NV, et al. Global transcriptional control by glucose and carbon regulator CcpA in Clostridium difficile. Nucl Acids Res. 2012;40(21):10701-18.

19. McKee RW, Mangalea MR, Purcell EB, Borchardt EK, Tamayo R. The Second Messenger Cyclic Di-GMP Regulates Clostridium difficile Toxin Production by Controlling Expression of sigD. J Bacteriol. 2013;195(22):5174-85.

20. Selby CP, Sancar A. Gene- and strand-specific repair in vitro: partial purification of a transcription-repair coupling factor. Proc Natl Acad Sci U S A. 1991;88(18):8232-6.

21. Deaconescu AM, Sevostyanova A, Artsimovitch I, Grigorieff N. Nucleotide excision repair (NER) machinery recruitment by the transcription-repair coupling factor involves unmasking of a conserved intramolecular interface. Proc Natl Acad Sci U S A. 2012;109(9):3353-8.

22. Deaconescu AM, Chambers AL, Smith AJ, Nickels BE, Hochschild A, Savery $\mathrm{NJ}$, et al. Structural basis for bacterial transcription-coupled DNA repair. Cell. 2006;124(3):507-20.

23. Saxowsky TT, Doetsch PW. RNA polymerase encounters with DNA damage: transcription-coupled repair or transcriptional mutagenesis? Chem Rev. 2006;106(2):474-88.

24. Zalieckas JM, Wray Jr LV, Ferson AE, Fisher SH. Transcription-repair coupling factor is involved in carbon catabolite repression of the Bacillus subtilis hut and gnt operons. Mol Microbiol. 1998;27(5):1031-8.

25. Belitsky BR, Sonenshein AL. Roadblock repression of transcription by Bacillus subtilis CodY. J Mol Biol. 2011;411(4):729-43.

26. Willing SE, Candela T, Shaw HA, Seager Z, Mesnage S, Fagan RP, et al. Clostridium difficile surface proteins are anchored to the cell wall using CWB2 motifs that recognise the anionic polymer PSII. Mol Microbiol. 2015;96(3):596-608.

27. Reynolds CB, Emerson JE, de la Riva L, Fagan RP, Fairweather NF. The Clostridium difficile cell wall protein CwpV is antigenically variable between strains, but exhibits conserved aggregation-promoting function. PLoS Pathog. 2011;7(4):e1002024.

28. Dembek M, Reynolds CB, Fairweather NF. Clostridium difficile cell wal protein CwpV undergoes enzyme-independent intramolecular autoproteolysis. J Biol Chem. 2012;287(2):1538-44.

29. Sebaihia M, Wren BW, Mullany P, Fairweather NF, Minton N, Stabler R, et al. The multidrug-resistant human pathogen Clostridium difficile has a highly mobile, mosaic genome. Nat Genet. 2006;38(7):779-86.
30. Emerson J, Reynolds CB, Fagan RP, Shaw HA, Goulding D, Fairweather NF. A novel genetic switch controls phase variable expression of CwpV, a Clostridium difficile cell wall protein. Mol Microbiol. 2009;74:541-56.

31. Lyras D, O'Connor JR, Howarth PM, Sambol SP, Carter GP, Phumoonna T, et al. Toxin $B$ is essential for virulence of Clostridium difficile. Nature. 2009:458(7242):1176-9.

32. Torres J, Camorlinga-Ponce M, Munoz O. Sensitivity in culture of epithelial cells from rhesus monkey kidney and human colon carcinoma to toxins $A$ and B from Clostridium difficile. Toxicon. 1992;30(4):419-26.

33. Deaconescu AM, Savery N, Darst SA. The bacterial transcription repair coupling factor. Curr Opin Struct Biol. 2007;17(1):96-102.

34. Ross C, Pybus C, Pedraza-Reyes M, Sung HM, Yasbin RE, Robleto E. Novel role of $\mathrm{mfd}$ : effects on stationary-phase mutagenesis in Bacillus subtilis. J Bacteriol. 2006;188(21):7512-20.

35. Han J, Sahin O, Barton Y-W, Zhang Q. Key role of Mfd in the development of fluoroquinolone resistance in Campylobacter jejuni. PLoS Pathog. 2008;4(6):e1000083.

36. Antunes A, Martin-Verstraete I, Dupuy B. CcpA-mediated repression of Clostridium difficile toxin gene expression. Mol Microbiol. 2011;79(4):882-99.

37. Paredes CJ, Alsaker KV, Papoutsakis ET. A comparative genomic view of clostridial sporulation and physiology. Nat Rev Microbiol. 2005;3(12):969-78.

38. de la Riva L, Willing SE, Tate EW, Fairweather NF. Roles of cysteine proteases Cwp84 and Cwp13 in biogenesis of the cell wall of Clostridium difficile. J Bacteriol. 2011;193(13):3276-85.

39. Calabi E, Ward S, Wren B, Paxton T, Panico M, Morris H, et al. Molecular characterization of the surface layer proteins from Clostridium difficile. Mol Microbiol. 2001;40(5):1187-99.

40. Sambrook J, Fritsch EF, Maniatis T. Molecular cloning. Cold Spring Harbor, New York: Cold Spring Harbor Press; 1989.

41. Heap JT, Kuehne SA, Ehsaan M, Cartman ST, Cooksley CM, Scott JC, et al. The ClosTron: Mutagenesis in Clostridium refined and streamlined. J Microbiol Meth. 2010;80(49-55):49-55

42. Heap JT, Pennington OJ, Cartman ST, Carter GP, Minton NP. The ClosTron: A universal gene knock-out system for the genus Clostridium. J Microbiol Meth. 2007:70(3):452-64.

43. Kuehne SA, Cartman ST, Heap JT, Kelly ML, Cockayne A, Minton NP. The role of toxin $A$ and toxin B in Clostridium difficile infection. Nature. 2010:467:711-3.

\section{Submit your next manuscript to BioMed Central and we will help you at every step:}

- We accept pre-submission inquiries

- Our selector tool helps you to find the most relevant journal

- We provide round the clock customer support

- Convenient online submission

- Thorough peer review

- Inclusion in PubMed and all major indexing services

- Maximum visibility for your research

Submit your manuscript at www.biomedcentral.com/submit 